\title{
Discapacidad intelectual: análisis crítico de la interdicción por demencia en Chile
}

\author{
Fabiola Latbrop Gómez*
}

\section{RESUMEN}

Este artículo analiza críticamente las normas respecto de interdicción por demencia chilenas, en especial, los procedimientos de distinta naturaleza que la sustancian y los efectos negativos que ello genera. Esta crítica espera contribuir a una futura construcción de sistemas de apoyo y salvaguardas para el ejercicio de la capacidad jurídica por parte de las personas con discapacidad intelectual acordes a un Estado democrático de Derecho.

Discapacidad intelectual - interdicción por demencia - sistemas de apoyo y salvaguardas

\section{Intellectual disability: critical analysis of the legal incapacity by insanity in Chile}

\begin{abstract}
This article makes a critical assessment of the Chilean law on interdiction by dementia, the different procedures that give it substance and the negative effects they produce, with the goal of contributing to the creation of support systems and safeguards for people with intellectual disability to exercise their legal capacity in conformity with a democratic state of law.
\end{abstract}

Intellectual disability - interdiction by dementia - support systems and safeguards

* Licenciada en Ciencias Jurídicas y Sociales, Universidad de Chile. Doctora en Derecho, Universidad de Salamanca. Profesora de Derecho Civil, Universidad de Chile. Correo electrónico: flathrop@derecho.uchile.cl.

Artículo recibido el 13 de agosto de 2018 y aceptado para su publicación en este número el 18 de enero de 2019. 


\section{INTRODUCCIÓN}

$\mathrm{L}$ a discapacidad intelectual se ha definido, a la luz del artículo 1, inciso segundo, de la Convención sobre los Derechos de las Personas con Discapacidad ${ }^{1}$ (Convención), como "la resultante de la interacción entre algunas condiciones psíquicas y/o intelectuales de largo plazo que pueden presentar las personas, y las barreras del entorno, tales como formas de exclusión social, carencias de apoyo y actitudes estigmatizadoras, que limitan su participación plena y efectiva en la sociedad, en igualdad de condiciones con las demás" 2 .

Actualmente se prefiere agregar a esta denominación las de discapacidad "cognitiva" y "psicosocial”, pues todas ellas describen mejor la situación en que se encuentran estas personas ${ }^{3}$. La "discapacidad cognitiva” es una distinción relativamente nueva, que se relaciona parcialmente con las de discapacidad mental e intelectual; se trata de un conjunto de condiciones que afectan el desarrollo y adaptación social de algunas personas. Está asociada a una condición que, generalmente, surge después de los dieciocho años, o bien, antes de esa edad como resultado de algún daño cerebral; e incluye a personas que han experimentado derrames cerebrales, demencias o mal de Alzheimer y a adultos mayores con otras formas de disminución cognitiva debido a su edad. A su vez, la "discapacidad psicosocial" está más bien ligada a un problema de salud mental y envuelve también la discapacidad mental de causa psíquica; incluye a las personas que son identificadas usualmente como "usuarios de la salud mental", "sobrevivientes psiquiátricos" o "locos" 4 .

Entre las dificultades asociadas a la discapacidad intelectual están las psicolingüísticas y de pensamiento lógico; el autismo, la disfasia y los síndromes de Down y Asperger son comúnmente vinculados a la discapacidad intelectual, aunque también pueden denominarse "trastornos del desarrollo".

En nuestro contexto, el artículo 9 letra c) del Decreto 47 del Ministerio de Salud, que aprueba Reglamento para la calificación y certificación de la discapacidad, señala a la "deficiencia mental" como una condición de salud que puede causar discapacidad, clasificándola en: "deficiencia mental de causa psíquica”, que sería aquella que presentan las personas que padecen trastornos en el comportamiento adaptativo, previsiblemente permanentes, derivada de una enfermedad psíquica; y "deficiencia mental de causa intelectual”, que sería aquella que presentan las personas cuyo rendimiento intelectual es inferior a la norma en test estandarizados. Me parece que lo que este Decreto define como deficiencia mental de causa psíquica correspondería a lo que en este trabajo se entiende por discapacidad psicosocial. A su vez, la deficiencia mental de causa intelectual que define el Decreto correspondería a lo que entiendo por discapacidad intelectual.

${ }^{1}$ Convención sobre los Derechos de las Personas con Discapacidad, adoptada el 13 de diciembre de 2006. Ratificada por Chile mediante Decreto 201, publicado el 17 de septiembre de 2008.

${ }^{2}$ Observatorio de Derechos Humanos de las Personas con Discapacidad Mental, 2014, p. 14.

3 Cfr. Fundación Descúbreme, 2018.

${ }^{4}$ Cfr. Bach y KerZner 2010, pp. 14-16. 
A lo largo de este trabajo me referiré a las personas con discapacidad intelectual con la frase "personas con discapacidad intelectual, cognitiva y/o psicosocial" (PcDICPS).

Las personas con discapacidad son víctimas de limitaciones en el desarrollo de sus vidas. Dentro de ellas, las PcDICPS se encuentran en una situación doblemente especial. Primero, porque su discapacidad puede ser inaparente (a diferencia de alguna discapacidad física), lo que impide brindar el apoyo pertinente con facilidad 5 . En segundo lugar, porque deben luchar por derribar distintas barreras en el ejercicio de su capacidad jurídica, partiendo por el hecho de que, bajo la legislación civil, se les pueda considerar como incapaces absolutos si se entendiera que son "dementes" y eventualmente declarárseles interdictas por demencia.

Como es sabido, en relación con la capacidad de ejercicio, nuestra legislación señala que "Toda persona es legalmente capaz, excepto aquellas que la ley declara incapaces" (artículo 1446 del Código Civil -CC-), distinguiendo entre los absoluta y los relativamente incapaces: "Son absolutamente incapaces los dementes, los impúberes y los sordos o sordomudos que no pueden darse a entender claramente" (artículo 1447 inciso primero del CC) ${ }^{6}$.

La legislación general y especial continúa utilizando denominaciones arbitrarias para referirse a las PcDICPS y, más aún, la ley civil no ha adecuado sus reglas pertinente a capacidad e interdicción por demencia a los postulados de la Convención, en especial a los párrafos 1 y 2 de su artículo $12^{7}$. Las PcDICPS se ven enfrentadas a barreras legales y a prácticas discriminatorias que atentan contra su dignidad en ámbitos de su libertad personal, relaciones familiares, salud, relaciones contractuales, derechos políticos y acceso a ciertos cargos y funciones.

En este trabajo analizo críticamente las normas acerca de interdicción por demencia, en especial los procedimientos de distinta naturaleza que la sustancian y los efectos negativos que ello genera. Para este efecto he revisado la doctrina chilena especializada existente -que es escasa, por cierto-, documentos de diagnóstico de algunas instituciones vinculadas al sistema de justicia, datos estadísticos y, en especial, la jurisprudencia de los tribunales superiores referida a situaciones de presuntos "dementes". Asimismo,

${ }^{5}$ Si se analiza la aplicación de la Ley $\mathrm{N}^{\mathrm{o}} 20.609$, el mayor porcentaje de ingresos de este tipo de causas responde a acciones por hechos de discriminación en razón de "enfermedad o discapacidad" contra los afectados, con $39 \%$ del total de causas en primera instancia, manteniéndose la tendencia con $37 \%$ de los recursos en Cortes de Apelaciones y $67 \%$ en Corte Suprema. Esto, según datos proporcionados por la DiRECCIÓN DE Estudios de la Corte Suprema (2017) p. 28. Recientemente, en sentencia de Corte Suprema, 21.6.2018, rol 38521-2017, conociendo de una casación en el fondo recaída en causa sobre acción de discriminación de la Ley $N^{\circ} 20.609$, se ordenó a un colegio pagar una multa de 50 UTM por discriminar a un alumno con síndrome de Down que no había sido promovido a primero básico. referida.

${ }^{6}$ Los énfasis han sido añadidos en esta y en las demás normas citadas, así como en la jurisprudencia

${ }^{7}$ El artículo 12 de la Convención señala que: "1. Los Estados Partes reafirman que las personas con discapacidad tienen derecho en todas partes al reconocimiento de su personalidad jurídica.

2. Los Estados Partes reconocerán que las personas con discapacidad tienen capacidad jurídica en igualdad de condiciones con las demás en todos los aspectos de la vida”. 
he accedido a algunos expedientes de interdicción por demencia de juzgados civiles de Santiago con el objeto de detectar sus características ${ }^{8}$.

En suma, este trabajo busca contribuir dogmáticamente a la futura creación e implementación de un marco normativo que promueva la vida independiente en comunidad de las PcDICPS en el contexto de un Estado democrático de Derecho, mediante la construcción de sistemas de apoyo y salvaguardas al ejercicio de su capacidad jurídica respetuosos de su voluntad, deseos y preferencias ${ }^{9}$.

\section{La CuRAduría del Demente. Concepto y ReQuisitos}

Las normas generales respecto de la capacidad jurídica chilenas son complementadas por un sistema de declaración de interdicción y regulación de las curadurías contenido en los Títulos XXV y XXVI del Libro I del CC ("Reglas especiales relativas a la curaduría del demente" y "Reglas especiales relativas a la curaduría del sordo o sordomudo", respectivamente).

La Corte de Apelaciones de Santiago, en sentencia rol 9316-15, de 5 de noviembre de 2015, ha señalado que las curatelas son "cargos impuestos a ciertas personas a favor de aquellos que no pueden dirigirse a sí mismos o administrar competentemente sus negocios, de lo que se sigue que la intención del legislador fue proteger a esas personas de los peligros a que se hallan expuestos en razón de su condición, particularmente en lo que concierne a su manejo personal y a la administración de sus bienes" (considerando 2).

La PcDICPS que ha sido declarada interdicta por demencia será representada por un curador general ${ }^{10}$ en todos los actos judiciales y extrajudiciales que le conciernan y que puedan menoscabar sus derechos o imponerle obligaciones (artículo 390 del CC) ${ }^{11}$.

${ }^{8}$ Tanto la jurisprudencia como los expedientes son posteriores a 2010. Ello, porque el 10 de febrero de 2010 fue publicada la Ley $\mathrm{N}^{\circ}$ 20.422, que establece normas sobre igualdad de oportunidades e inclusión social de personas con discapacidad, por lo que esperaba detectar algún impacto de tal ley en la ponderación judicial. Para recoger una muestra socioeconómica representativa de lo que ocurre en la capital se revisaron causas con patrocinio de la CAJ como particular. Agradezco a la jueza civil Carolina Taeko y al abogado de CAJ Héctor Droguett por haberme proporcionado acceso a algunos expedientes. A Constanza Canepa, Isaac Ramírez y Maximiliano Barros por haber colaborado como ayudantes de cátedra en su análisis.

9 América Latina está presentando avances en esta materia. Así, Perú acaba de dictar el Decreto Legislativo 1384 que reconoce y regula la capacidad jurídica de las personas con discapacidad en igualdad de condiciones, el que modifica el Código Civil creando un sistema de apoyos y salvaguardas para el ejercicio de tal capacidad jurídica. Asimismo, Costa Rica ha hecho lo propio en 2016 mediante Ley 9.379 para la Promoción de la Autonomía Personal de las Personas con Discapacidad; y Colombia discute actualmente un proyecto de ley en tal sentido.

${ }^{10}$ El CC, en su artículo 340, establece que: "Están sujetos a curaduría general los menores adultos; los que por prodigalidad o demencia han puesto en entredicho de administrar sus bienes; y los sordos o sordomudos que no pueden darse a entender claramente".

11 "Toca al tutor o curador representar o autorizar al pupilo en todos los actos judiciales o extrajudiciales que le conciernan, y puedan menoscabar sus derechos o imponerle obligaciones". 
El artículo 456 del CC establece que "El adulto que se halla en un estado habitual de demencia, deberá ser privado de la administración de sus bienes, aunque tenga intervalos lúcidos. La curaduría del demente puede ser testamentaria, legítima o dativa”.

Tres son los requisitos para declarar la interdicción por demencia ${ }^{12}$ : que el sujeto sea demente; que sea adulto o menor adulto, dependiendo de la posición a la que se adscriba; y que la demencia exista en un estado de habitualidad, aun cuando se observen intervalos de lucidez ${ }^{13}$.

En cuanto al primer requisito, y sin perjuicio de lo desarrollado anteriormente respecto de los conceptos de discapacidad intelectual, cognitiva y psicosocial, en cuanto a la noción de "demencia", ella no es unívoca, existiendo distintas acepciones según la disciplina que la utilice. Así, el Plan Nacional de Demencia de $2017^{14}$ señala que es una condición adquirida y crónica, caracterizada por un deterioro de diversas funciones cerebrales, sin distinción de sexo, que se acompaña de síntomas cognitivos, psicológicos y cambios conductuales. En el ámbito jurídico, a su vez, los conceptos de "demente" y de "demencia" son ambiguos. En efecto, Claro Solar ${ }^{15}$ señalaba que la ley designa con la palabra "dementes" a "toda persona que por el trastorno de sus facultades mentales o la privación constante o momentánea de su razón se halla impedida de tener la libre voluntad de obligarse, no discierne, ni puede asumir la responsabilidad de sus actos". Corral Talciani ${ }^{16}$, más recientemente, ubica a la "demencia" en dos contextos distintos: "la expresión 'demencia' en el contexto de las normas relativas a la interdicción se debe entender en el sentido abierto, no técnico y amplio propiciado desde antiguo por la doctrina, y hoy configurado dentro del concepto genérico de la discapacidad mental". En otros contextos distintos de la interdicción, la demencia "debe ser entendida en el concepto más preciso de privación actual de la razón. Por ello, en estos casos, no se considerará demente al discapacitado mental sino únicamente a aquel que en el momento de realizar la conducta descrita por la ley estaba privado de razón o del entendimiento necesario para determinar sus actos".

El segundo requisito plantea problemas doctrinarios. El artículo 457 del CC señala que "cuando el niño demente haya llegado a la pubertad, podrá el padre de familia seguir cuidando de su persona y bienes hasta la mayor edad; llegada la cual deberá precisamente provocar el juicio de interdicción”. Esta norma permite una suerte de interdicción de pleno derecho del menor adulto sujeto a patria potestad que llega a la pubertad con algún grado de "demencia"; no media en este caso intervención de autoridad

${ }^{12}$ Cfr. BARCia, 2011, p. 546.

${ }^{13}$ Carlos López afirma que a la época de la dictación del Código no existían conocimientos científicos suficientes como para verificar la existencia de los intervalos lúcidos "que hoy la ciencia moderna considera inexistentes". LópEz, 2016, pp. 663-664.

${ }^{14}$ Ministerio de Salud, 2017, p. 11.

15 Cfr. Claro, 1979, p. 27.

${ }^{16}$ Cfr. Corral, 2011, p. 49. 
administrativa o judicial alguna que verifique la supuesta situación de demencia, lo que vulnera su derecho a ser oído y al debido proceso, entre otros ${ }^{17}$.

A lo anterior se suma lo dispuesto en el artículo 458 del CC: "El tutor del pupilo demente no podrá después ejercer la curaduría sin que preceda interdicción judicial, excepto por el tiempo que fuere necesario para provocar la interdicción.

Lo mismo será necesario cuando sobreviene la demencia al menor que está bajo curaduría”.

En esta última norma, el legislador entiende que la curaduría de un demente tiene efectos distintos a los de la curaduría del menor adulto y un fundamento distinto al de la tutela del impúber. Por ello previene que el tutor de un impúber demente no podrá seguir ejerciendo la curaduría después de llegada la mayoría de edad, salvo que obtenga la declaración judicial de interdicción. Nuevamente, se consagra una especie de interdicción de pleno derecho durante el tiempo necesario para provocar la interdicción, es decir, hasta llegada la mayoría de edad. La norma es una reiteración de lo dispuesto en el artículo 457 del CC para los casos en que la persona no esté sujeta a patria potestad.

En doctrina se discute qué sucede con el menor adulto supuestamente "demente", pues antes de llegar a la pubertad se es incapaz absoluto igualmente. En el caso de que una persona esté sujeta a patria potestad y padezca "demencia” antes de llegar a la pubertad, no existirá declaración de interdicción, porque la condición de impúber ya sitúa a la persona como incapaz absoluto.

Lyon Puelma ${ }^{18}$ sostiene que a causa de que el menor adulto puede trabajar y ser titular de derechos sobre bienes propios que administra personalmente, puede provocarse su interdicción por demencia. Silva Barroilhet ${ }^{19}$, en cambio, afirma que ella solo puede ser provocada contra mayores de edad, debido a varias razones: el tenor literal del artículo 456 del CC, que habla de "adultos"; el que la interdicción por demencia de un menor de edad solo se podría obtener respecto de la administración de los frutos del trabajo del pupilo porque, no habiendo cumplido los 18 años y no estando sujeto a patria potestad, lo estará a la tutela o curaduría del menor adulto; finalmente, el artículo 457 del CC consigna la obligatoriedad de provocar el juicio de interdicción llegada la mayoría de edad, pero no antes. Adhiero a esta postura por ser más garantista de los derechos de menores de edad -que requieren protección reforzada por parte del Estado-, en cuanto interpreta las normas permitiendo al menos retardar el cercenamiento de tales derechos por medio de la interdicción.

${ }^{17}$ Este caso no constituiría una guarda propiamente tal, debido a que: a) falta discernimiento, requisito esencial para el ejercicio de la guarda según el artículo 373 del CC; y b) esta suerte de guarda se ejercería por el padre o la madre que tienen la patria potestad, lo que excluiría la existencia de una curaduría.

18 Cfr. LyON, 2007, p. 180.

${ }^{19}$ Cfr. Silva, 2017, pp. 147-148. 


\section{LOS PROCEDIMIENTOS DE INTERDICCIÓN}

Existen dos procedimientos judiciales para provocar la interdicción de una PcDICPS:

a) el juicio de interdicción, contencioso, de lato conocimiento, al que se refieren el CC y el Código de Procedimiento Civil (CPC) ${ }^{20}$;

b) el procedimiento voluntario de interdicción consagrado en el artículo 4 inciso segundo de la Ley $N^{0} 18.600$ que Establece Normas sobre Deficientes Mentales ${ }^{21}$.

Además, existe un procedimiento de carácter administrativo contemplado en esta última ley, que examinaré más adelante.

\section{Titularidad activa}

El artículo 459 del CC señala quiénes podrán provocar el juicio de interdicción por demencia, remitiéndose a la interdicción del disipador-artículo 443 del CC-; es decir: el cónyuge no separado judicialmente del supuesto demente; cualquiera de sus consanguíneos hasta el cuarto grado; y el defensor público. Sin embargo, el inciso tercero agrega: "Pero si la locura fuere furiosa, o si el loco causare notable incomodidad a los habitantes, podrá también el procurador de ciudad o cualquiera del pueblo provocar la interdicción”; permitiendo así una suerte de acción pública ${ }^{22}$.

En mi opinión, denominaciones como "demente" y "loco" deben ser desterradas de nuestra legislación por ser lesivas de la dignidad humana ${ }^{23}$. Además, el artículo 459 inciso tercero del CC es amplio: una textura así de abierta puede dar lugar a arbitrariedades tanto del particular como del juez. Asimismo, la posibilidad de que el texto de la norma permita que cualquier habitante genere la interdicción es desproporcionado, en especial, considerando las consecuencias que ello acarrea para la supuesta persona "demente". Probablemente sea un concepto de escasa utilización, aunque aun así es reprochable que continúe vigente en nuestro ordenamiento.

En cuanto al procedimiento voluntario, el artículo 4 inciso segundo de la Ley $\mathrm{N}^{\circ} 18.600$ establece una titularidad activa distinta: podrá solicitar la interdicción el

${ }^{20}$ No se debe confundir este juicio contencioso con las normas del Título VI del Libro IV del CPC. Este último se refiere propiamente al nombramiento del guardador que tendrá lugar, mediante el discernimiento, una vez que se haya obtenido declaración de interdicción. El nombramiento del guardador es un acto, en principio, no contencioso; no así el juicio de interdicción, que será contencioso siempre que se interponga demanda o no se acompañe la certificación vigente inscrita en el Registro Nacional de la Discapacidad.

${ }^{21}$ Inciso agregado por la Ley $\mathrm{N}^{\circ} 19.954$, de 2004.

22 Cfr. Silva, 2017, p. 147.

${ }^{23}$ El Comité sobre los Derechos de las Personas con Discapacidad, en el párrafo 5 de las Observaciones finales sobre el informe inicial de Chile, de 13 de abril de 2016, señala: "Al Comité le preocupa la ausencia de una estrategia para la armonización legislativa relativa a personas con discapacidad, así como la persistencia del modelo médico y el uso de terminología peyorativa tales como "invalidez", "incapaces" y “dementes" en normas vigentes incluido el Código Civil y la ley 20.422 de 2010”. 
padre o la madre y, si ejercen el cuidado en conjunto, podrá la curaduría ser deferida a ambos; en caso de ausencia o impedimento de los padres, podrá ser solicitada por los parientes más cercanos, sin perjuicio de lo dispuesto en el artículo 18 bis que analizaré luego (que consagra una curaduría provisoria). Como se aprecia, este artículo, a diferencia del Código Civil, no limita el grado de parentesco, por lo que podría ser ejercida por cualquier pariente, mientras sea el más cercano. De esta forma, la norma excluye a los cónyuges y, por cierto, tampoco menciona al defensor público ni contempla esa especie de acción pública que establece el artículo 459 del CC.

\section{Prelación en la curaduría del demente}

El artículo 462 del CC establece un orden de prelación para el caso de la guarda legítima ${ }^{24}$ :

"Se deferirá la curaduría del demente:

$1^{\circ}$. A su cónyuge no separado judicialmente, sin perjuicio de lo dispuesto en el artículo 503;

$2^{\circ}$. A sus descendientes;

$3^{\circ}$. A sus ascendientes, pero el padre o madre cuya paternidad o maternidad haya sido determinada judicialmente contra su oposición o que esté casado con un tercero no podrá ejercer el cargo;

$4^{\circ}$. A sus hermanos, $y$

$5^{\circ}$. A otros colaterales hasta en el cuarto grado".

El inciso segundo del artículo 462 del CC señala que el juez determinará la persona o personas más idóneas cuando exista más de una opción en las categorías $\mathrm{N}^{\mathrm{os}} 2,3,4$ y 5 .

Este orden de prelación es aplicable al nombramiento del guardador provocado por un juicio contencioso de interdicción. Como señalé anteriormente, el artículo 4 inciso segundo de la Ley $\mathrm{N}^{\circ} 18.600$ establece para el procedimiento voluntario, en cambio, que podrá solicitar la interdicción el padre o la madre y, si ejercen el cuidado en conjunto, podrá la curaduría ser deferida a ambos; en caso de ausencia o impedimento de los padres, podrá ser solicitada por los parientes más cercanos.

\section{Sustanciación contenciosa o no contenciosa}

La tramitación del procedimiento de interdicción por demencia dependerá de la vía por la que se inicie: si es con una solicitud voluntaria que acompaña la certificación vigente e inscrita en el Registro Nacional de la Discapacidad (RND), se le dará la

${ }^{24}$ Que la guarda sea legítima significa que este orden de prelación opera a falta de designación testamentaria, pues la persona llamada a ejercer la guarda por testamento tendrá preferencia para asumir el cargo; cuando ninguna de las personas mencionadas pueda ejercer la curaduría, tendrá lugar la guarda dativa. 
tramitación de la Ley $\mathrm{N}^{\circ} 18.600$; si se hace por medio de una demanda sin acompañar tal certificación, se le dará tramitación contenciosa ${ }^{25}$.

Así, la demanda debiera implicar que el procedimiento se sustanciará -en principio- según las reglas del juicio ordinario del Libro II del CPC. Ello se deduce a falta de norma que ordene sustanciación especial o sumaria de forma expresa y de la redacción de ciertos artículos como, por ejemplo, el artículo 460 del CC (según este, el juez "debe informarse" de la conducta habitual y vida anterior de la persona, lo que hace inferir la necesidad de un juicio de lato conocimiento). En cambio, si se acompaña la mencionada certificación, se siguen las reglas especiales del artículo 4 de la Ley $\mathrm{N}^{\circ}$ 18.600, aunque podría el juez ordenar la sustanciación contenciosa, según las reglas del procedimiento sumario, no obstante no esté expresamente permitido por la ley, considerando cierta jurisprudencia que comento a continuación.

El CPC señala que cuando el procedimiento se haya iniciado como voluntario y exista oposición de legítimo contradictor ${ }^{26}$, operará una sustitución del procedimiento y se le dará tramitación contenciosa ${ }^{27}$. Así ocurrió en un caso conocido por la Corte Suprema, en que se ordenó sustitución del procedimiento según las reglas del juicio sumario ${ }^{28}$, probablemente porque la Corte estimó que la discapacidad ya se encontraba acreditada por la inscripción del certificado -emitido por la Comisión de Medicina Preventiva e Invalidez (COMPIN) - en el RND. En este caso, la conviviente de hecho del presunto demente se había opuesto a la pretensión de la parte solicitante. En primera instancia se le reconoció la calidad de parte, pero como tercero coadyuvante. En su fallo sobre la casación en el fondo, la Corte Suprema le niega esta calidad.

Entonces, conforme con esta jurisprudencia, corresponderá reformular el procedimiento como uno contencioso ante la oposición de un tercero, pero no considerarlo un tercero coadyuvante, cuya pretensión siempre debe adherir a alguna de las pretensiones principales. Esto reviste importancia procedimental, toda vez que el tribunal de primera instancia habría errado al sustituir el procedimiento, lo que habría provocado - de no ser

${ }^{25}$ La gran mayoría de las causas revisadas a efectos de este trabajo eran voluntarias, salvo una con patrocinio particular en que el procedimiento se torna contencioso pues existe oposición a la solicitud de interdicción por parte de otros parientes. Consecuentemente, en esta causa se presentaron recursos, tanto de apelación como casación, contra la decisión del juez civil; lo que, a su vez, produjo que el juicio se extendiera más en el tiempo que en los otros casos. La litigiosidad de esta causa podría deberse a que existe interés por parte del grupo familiar respecto de quién administrará el patrimonio del interdicto.

26 Por legítimo contradictor entenderemos a aquella persona que tiene "derecho" a oponerse a la solicitud voluntaria. En concreto, se trata de una cuestión de legitimación activa y de prelación para el ejercicio de la guarda. Si, por ejemplo, un hijo o hija solicita la interdicción mediante un procedimiento voluntario y la PcDICPS está casada, podrá el cónyuge de la persona con discapacidad oponerse, y dicha oposición será legítima.

27 Artículo 823 del CPC: "Si a la solicitud presentada se hace oposición por legítimo contradictor, se hará contencioso el negocio y se sujetará a los trámites del juicio que corresponda.

Si la oposición se hace por quien no tiene derecho, el tribunal, desestimándola de plano, dictará resolución sobre el negocio principal".

${ }^{28}$ Corte Suprema, 17.12.2015, rol 27322-2014. 
revocada la sentencia- que un procedimiento verdaderamente contencioso se tramitara como una gestión voluntaria.

\section{Efecto de la declaración judicial de interdicción por demencia}

El efecto de la declaración de interdicción por demencia es el mismo, sea que el procedimiento por el que se sustancie sea contencioso o administrativo: la persona queda interdicta. Sin embargo, el artículo 4 de la Ley $\mathrm{N}^{\circ} 18.600$ hace algunas excepciones a la sustitución absoluta de voluntad que acarrea la interdicción, reconociendo cierta capacidad a las PcDICPS -que en ningún caso subsana las falencias del sistema-. Esta norma hace aplicables los artículos 440 y 453 del CC y otorga un especial "permiso" al interdicto.

El artículo 440 del CC permite que el guardador confíe al pupilo la administración de alguna parte de su patrimonio; a su vez, el artículo 453 del CC obliga al juez a fijar una suma de dinero de libre disposición para el pupilo. No obstante, el inciso segundo del mencionado artículo 4 especificaría que es el curador quien fija la suma, prudencialmente. Por aplicación del principio de especialidad de la ley, esta última opción debiera primar; aunque es reprochable que la determinación de si recibe dinero y en qué cantidad quede relegada a la prudencia del curador (la intervención judicial podría dar mejor garantía, en el contexto ya reprochable de la sustitución de la voluntad, de la concesión de tal dinero).

Por otra parte, el inciso segundo del artículo 4 de la Ley $\mathrm{N}^{\circ} 18.600$ permite suscribir contratos de trabajo, con autorización del guardador, suscripción que no está prevista cuando la interdicción se provoque por juicio contencioso de interdicción.

Finalmente, es posible señalar que en 2016 el Tribunal Constitucional conoció una solicitud de declaración de inaplicabilidad por inconstitucionalidad del artículo 456 del CC y del artículo 4 de la Ley $\mathrm{N}^{\circ} 18.600$ para que surtiera efectos en una gestión voluntaria de interdicción por demencia. Esta gestión pendiente se refería a la petición de una madre de declarar a su hijo de 20 años interdicto por demencia, el que sufría una discapacidad que le afectaba en sus actividades psíquicas en 30\%. La petición se había fundado en los artículos 459 y 443 del CC y en el mencionado artículo 4, señalando que con su aplicación se vulneraba el derecho a la igualdad, invocando también la Convención mediante el artículo 5 de la Carta Fundamental -especialmente su artículo 12_ ${ }^{29}$.

El Tribunal Constitucional rechazó la solicitud argumentando que la naturaleza de la acción de inaplicabilidad por inconstitucionalidad impediría efectuar juicios de valor o de mérito sobre la legislación porque: 1) la constitucionalidad de la ley se presume; 2) los juicios de mérito sobre la obra legislativa están fuera de su competencia; 3) el deber que adquiere el Estado de adecuar su normativa interna a las normas contenidas en tratados internacionales corresponde a los órganos colegisladores (considerando 6).

Por otra parte, el Tribunal señaló que los tratados internacionales tienen un rango inferior a la Constitución y que no constituyen per se parámetros autónomos de control de

29 Tribunal Constitucional de Chile, 2.1.2016, rol 2703-15. 
constitucionalidad, en el sentido de habilitarla directamente para contrastar su sentido y alcance con los preceptos legales que presuntamente los contrarían (considerando 11). Afirmó también que existe una diferencia de trato entre personas capaces e incapaces que obliga al legislador a diseñar los mecanismos necesarios para proteger a estas últimas, al tiempo que asegura la protección del interés social, de lo que no se sigue que se desconozca su capacidad de goce (considerando 15). Agregó que las normas impugnadas no producirían resultados contrarios a la Constitución y que una eventual adecuación de la legislación nacional a los parámetros derivados de la Convención debe ser efectuada por los órganos colegisladores (considerando 27).

Llama la atención que el Tribunal afirme que "la declaración de discapacidad conforme a la Ley $\mathrm{N}^{\mathrm{o}} 20.422$ otorga derecho a las acciones de prevención y rehabilitación que otorga el Estado, en apoyo de los incapaces, en las cuales la participación de la familia como de quienes los tengan a su cuidado es especialmente considerada (artículos 18 y 22). En el caso de una familia de escasos recursos, ese apoyo -más allá de la asistencialidad que pueda atribuírsele- puede resultar vital”. En este considerando (26), el Tribunal da a entender que la propia declaración de discapacidad y la consiguiente interdicción son un apoyo para la PcDICPS, sin reparar en la desproporcionalidad de la medida, vinculando inadecuadamente una situación socioeconómica precaria con la necesidad de tal declaración de discapacidad. ¿Las PcDICPS pobres que viven en familias que también lo son están justificadamente más proclives a la declaración de discapacidad y, por ende, a la de interdicción por demencia? Lamentablemente, el Tribunal justificó la existencia de una norma contraria a la Convención, avalando así la constitucionalidad de un sistema decimonónico de incapacidad y declaración de interdicción por demencia que vulnera la dignidad de las PcDICPS.

\section{5. ¿Salvaguardas de la interdicción por demencia?}

Teniendo en cuenta que el ordenamiento chileno no cuenta con un sistema de apoyos y salvaguardas para el ejercicio de la capacidad jurídica de las PcDICPS, podrían, eventualmente, entenderse como salvaguardias indirectas a la interdicción por demencia, algunas solemnidades y reglas que deben observarse para finalizar el proceso de interdicción y desempeñar la curaduría:

a) discernimiento del cargo, esto es, el decreto judicial que autoriza ejercerlo ${ }^{30}$;

b) lo obligación de rendir fianza ${ }^{31}$;

c) la obligación de confección de inventario solemne dentro de los 90 días subsiguientes al discernimiento ${ }^{32}$;

\footnotetext{
${ }^{30} \mathrm{CC}$, art. 373.

$31 \mathrm{CC}$, arts. 374 y 375.

32 CC, art. 378.
} 
d) administrar los bienes del pupilo estando obligado a su conservación, reparación y cultivo, debiendo responder por los actos ejecutados sin una diligencia mediana ${ }^{33}$;

e) el que la donación de bienes raíces del pupilo esté prohibida, aun con previo decreto judicial ${ }^{34}$;

f) la obligación de indemnizar al pupilo y la posibilidad de perseguir penalmente al curador por los delitos que haya cometido en el ejercicio de su cargo ${ }^{35}$.

Los procedimientos analizados hasta este momento no establecen mecanismos adecuados de defensa y apoyo a la PCDICPS, permitiéndose la imposición de un representante a las PcDICPS, que le sustituye en su voluntad. Asimismo, si bien puede recurrirse al juez para solicitar la remoción del guardador, ello exige costear una representación letrada que puede resultar gravosa tanto en términos patrimoniales como de tiempo; de manera que el control del modo en que tal representante ejerce sus funciones es insuficiente y de difícil acceso para la PcDICPS (como podría serlo si existiera una autoridad administrativa que ejerciera tal control o un defensor de los derechos de la PcDICPS). Esta remoción procede por: i) incapacidad; ii) fraude o culpa grave; iii) ineptitud manifiesta; iv) actos repetidos de administración descuidada ${ }^{36}$ y v) conducta inmoral de que pueda resultar daño a las costumbres del pupilo ${ }^{37}$. Puede ser provocada por cualquiera de los consanguíneos del pupilo, por su cónyuge y por cualquiera persona del pueblo. El juez podrá también promoverla de oficio ${ }^{38}$.

\section{Procedimiento administrativo contemplado en la Ley $N^{0} 18.600$}

El legislador del siglo XIX exigió el cumplimiento de los requisitos y la sustanciación de un procedimiento para la declaración de la interdicción por demencia que, con el transcurso del tiempo, devinieron, generalmente, en un obstáculo debido a su excesivo formalismo. Así, las normas legales relativas a la discapacidad han sufrido modificaciones a lo largo del tiempo y, en lo que respecta a la de tipo intelectual, la Ley $\mathrm{N}^{\circ} 18.600$ ha sido reformada de manera que hoy contempla un procedimiento judicial voluntario y otro administrativo para la tramitación de las interdicciones en el caso de las PcDICPS. El artículo 4 inciso primero de esta ley establece que la constatación, calificación, evaluación y declaración de la discapacidad mental, así como la certificación de esta, se hará de conformidad al procedimiento señalado en el Título II de la Ley $\mathrm{N}^{\circ} 19.284$ y en el reglamento ${ }^{39}$.

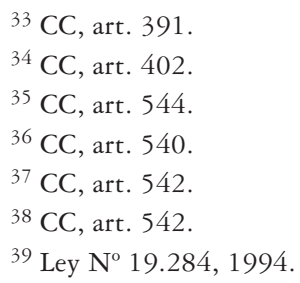


La Ley $\mathrm{N}^{\circ} 18.600$ buscó simplificar la obtención de la declaración de interdicción, atendiendo a que, en la práctica, en muchos casos, el cuidado de la PcDICPS se produce dentro del núcleo familiar y, llegada la mayoría de edad de ella, permanece viviendo con su familia. En este sentido, la provocación de un juicio de interdicción muchas veces implicaría un "falso" juicio ${ }^{40}$.

El artículo 18 bis de la Ley $\mathrm{N}^{\circ} 18.600^{41}$ establece una curaduría que se constituye conforme a un procedimiento administrativo, haciendo excepción al requisito de discernimiento de las guardas: "Las personas naturales o jurídicas que se encuentren inscritas en el Registro Nacional de la Discapacidad y que tengan a su cargo personas con discapacidad mental, cualquiera sea su edad, serán curadores provisorios de los bienes de estos, por el solo ministerio de la ley (...)". Según se ha señalado, esta norma da lugar a una suerte de guarda administrativamente constituida, que se ha prestado para abusos por parte de los cuidadores de las PcDICPS, que han preferido optar por esta alternativa para agilizar la curaduría y evitar trámites judiciales ${ }^{42}$.

El inciso segundo del señalado artículo 18 bis establece los requisitos de procedencia para esta curaduría provisoria:

a) Que la persona se encuentre bajo el cuidado permanente del solicitante. Se entiende que se cumple dicho requisito cuando: existe dependencia alimentaria, económica y educacional, diurna y nocturna; y dicha dependencia es parcial, es decir, por jornada, siempre y cuando esta haya tenido lugar de manera continua e ininterrumpida, durante dos años a lo menos;

b) Que carezcan de curador o no se encuentren sometidos a patria potestad;

c) Que la persona natural llamada a desempeñarse como curador provisorio o, en su caso, los representantes legales de la persona jurídica, no estén afectados por alguna de las incapacidades para ejercer tutela o curaduría que establece el párrafo $1^{\circ}$ del Título XXX del Libro Primero del CC.

La norma agrega, en el inciso cuarto, que si las circunstancias mencionadas constaren en el RND, bastará para acreditar la curaduría provisoria frente a terceros el certificado que expida el Servicio de Registro Civil e Identificación. En consecuencia, opera por el solo ministerio de la ley y, según lo estipulado en el inciso quinto del artículo 18 bis, no es necesario discernimiento, ni rendición de fianza o confección de inventario; además, estos curadores gozarán de privilegio de pobreza en las actuaciones judiciales

${ }^{40}$ Cfr. Silva, 2017, p. 149. En efecto, la totalidad de las causas revisadas a efectos de este trabajo han sido impulsadas por familiares: aquellas patrocinadas particularmente presentadas por hijos e hijas respecto de sus progenitores (las personas presuntamente "dementes" obedecen mayormente a hombres de aproximadamente 50 a 70 años). Las causas patrocinadas por CAJ son de un espectro más amplio, tanto de solicitantes como de presuntos interdictos: no solamente se solicita la interdicción de progenitores, sino también de sobrinos, sobrinas, madres, hijos, hijas y cónyuges, por parte de diversos familiares - no solamente hijos o hijas- (estas solicitudes dicen relación con personas que poseen un rango de edad más amplio).

${ }^{41}$ Este artículo fue incorporado mediante la Ley $\mathrm{N}^{\mathrm{o}} 19.735,2001$.

42 Cfr. Silva, 2017, pp. 153 y 155-160. 
y extrajudiciales que realicen en relación con esta curaduría y no percibirán retribución alguna por su gestión.

Respecto de la duración de esta curaduría, el inciso cuarto de la norma en comento establece que "La curaduría provisoria durará mientras permanezcan bajo la dependencia y cuidado de las personas inscritas en el Registro aludido y no se les designe curador de conformidad con las normas del Código Civil”. Así, esta curaduría es de duración indefinida y potencialmente permanente, ya que no establece una revisión obligatoria de tal calidad de dependencia y cuidado y queda, asimismo, sujeto a la voluntad de la persona que pasa a ser la curadora el generar un juicio de acuerdo con las reglas del CC.

Finalmente, y al igual que el procedimiento judicial voluntario, la legalidad de este procedimiento administrativo ha sido avalada por los órganos del Estado; esta vez por la Contraloría General de la República, en dictamen $N^{\circ} 27016$, de 10 de mayo de 2012, donde señaló que:

“(...) tampoco existe fundamento para sostener que la entrada en vigencia para nuestro país de la Convención (...) haya importado la derogación del sistema de curaduría en referencia, lo cual de acuerdo con los antecedentes adjuntos, se adujo como argumento para dejar de aplicarlo. En efecto, la norma especial del artículo 18 bis de la ley $\mathrm{N}^{\circ} 18.600$ propende a brindar una protección particular a los discapacitados a que ella se refiere, facilitando la administración de sus bienes por quienes los cuidan, lo cual se enmarca precisamente en el ámbito del artículo $12, \mathrm{~N}^{\mathrm{o}} 3$, de la convención en referencia”.

Una vez más, la referida norma de la Convención es incorrectamente interpretada en el sentido de que la sustitución de la voluntad mediante la interdicción es un apoyo para la PcDICPS, sin siquiera distinguir la intensidad de la discapacidad. Más reprochable es aun este pronunciamiento en el sentido de que avala la constitucionalidad de un trámite administrativo que no cuenta con un control de legalidad de carácter judicial (la limitación del ejercicio de derechos exige un examen de legalidad, razonabilidad y proporcionalidad de la medida, que la administración no efectúa según lo normado en la Ley $\left.\mathrm{N}^{\circ} 18.600\right)$.

\section{CRíticas a LOS PROCEDIMIENTOS DE INTERDICCIÓN POR DEMENCIA}

La existencia de dos procedimientos judiciales de declaración de interdicción de distinta naturaleza, sumada a la curaduría provisoria de índole administrativa, ha generado problemas importantes tanto de tramitación como de ponderación judicial.

En primer lugar, la imposibilidad de saber, a ciencia cierta, cuántas personas se encuentran declaradas interdictas por demencia en la actualidad. Según cifras del Instituto Nacional de Estadísticas -las más actualizadas a las que he podido acceder-, las causas terminadas con motivo de término "interdicción por demencia” en 2016 ascienden a 
912 (siendo las ingresadas 1.198$)^{43}$, pero no es posible precisar si en dichas causas se accede o no a la demanda y si se cumplieron las formalidades legales posteriores. Por otro lado, la existencia de una curaduría provisoria al margen de la intervención judicial que se prolonga de hecho en el tiempo provoca que haya interdicciones no registradas como tales o bien registros paralelos a lo ordenado judicialmente.

En segundo lugar, los tribunales no observan tramitaciones ni diligencias probatorias medianamente homogéneas. Si bien no puede exigirse razonablemente que los tribunales sustancien los procedimientos siempre de la misma forma, también es cierto que debe existir cierta seguridad en la tramitación que se observará. Así, se detecta que ante una misma solicitud las notificaciones y pruebas que se ordenan son distintas, generándose la consiguiente falta de seguridad jurídica en el usuario del sistema de justicia. Incluso, al menos hasta hace algunos años, existirían jueces que se niegan a sustanciar la interdicción como una gestión civil voluntaria -pese a caer dentro de la hipótesis de la Ley $\mathrm{N}^{\circ} 18.600{ }^{44}$.

En tercer lugar, se señala que como la Ley $\mathrm{N}^{\circ} 18.600$ no contempló los trámites posteriores al procedimiento que reguló, en la práctica, se subentiende que las diligencias y formalidades que contempla el CC para el ejercicio de la curaduría deben cumplirse de todas formas ${ }^{45}$. La Corporación de Asistencia Judicial (CAJ) ha concluido que: “(...) existe una fuerte corriente que plantea la necesidad de aplicar las ritualidades del antiguo sistema en cuanto a rendir fianza, practicar inventario, publicar en diario de circulación nacional e inscribir en el Conservador de Bienes Raíces, pues estos requerimientos fueron establecidos para proteger al interdicto y a los terceros respecto de los actos que este realice, dando certeza y seguridad jurídica" ${ }^{46}$. Con ello no se cumple el objetivo simplificador de las reformas a la Ley $\mathrm{N}^{\circ} 18.600$, existiendo situaciones en que se practican esas diligencias y formalidades y otras en que no se verifican.

En cuarto lugar, es posible observar que existe confusión entre el diagnóstico técnico acerca de la discapacidad intelectual, materializado frecuentemente en el certificado emitido por el profesional de la salud que corresponda -que se refiere a la calificación y certificación de la discapacidad ${ }^{47}$ - y la valoración que el juez, conociendo de una solicitud de interdicción, debe efectuar acerca de la competencia de la persona para

43 Instituto Nacional de Estadísticas, 2017, p. 9. Desde 2002 se observa una tendencia al aumento de este tipo de causas a nivel nacional.

${ }^{44}$ Corporación de Asistencia Judicial, 2012, p. 5.

45 Así lo ha expresado, entre otras, la sentencia de la Corte de Apelaciones de Copiapó, 12.12.2014, rol 397-2014.

${ }^{46}$ Corporación de Asistencia Judicial, 2012, p. 10.

47 Es importante recordar lo señalado en el artículo 9 letra c) del Decreto $\mathrm{N}^{\circ} 47$ del Ministerio de Salud, 2013: "deficiencia mental” es una condición de salud que puede causar discapacidad; clasificándola en: "deficiencia mental de causa psíquica": aquella que presentan las personas que padecen trastornos en el comportamiento adaptativo, previsiblemente permanentes, derivada de una enfermedad psíquica; y "deficiencia mental de causa intelectual": aquella que presentan las personas cuyo rendimiento intelectual es inferior a la norma en test estandarizados. 
tomar decisiones autónomas acerca de aspectos de su propia vida. A modo ejemplar, ello se detecta en los siguientes fallos.

En primer lugar, la sentencia de la Corte Suprema de 13 de julio de $2015^{48}$. Los antecedentes son los siguientes.

El 12 de marzo de 2014, el Juzgado Civil de La Calera conoció de una demanda ejecutiva por obligación de hacer, acogiendo la excepción del artículo 464 número 14 del CPC $^{49}$, entendiendo que había demencia habitual en el vendedor ejecutado. La compradora del supuesto demente alegaba incumplimiento de la obligación de entregar un inmueble que había comprado y que el vendedor era plenamente capaz al no encontrarse declarado interdicto por demencia mediante sentencia firme y ejecutoriada e inscrita en el competente registro conservatorio. La hermana del supuesto demente vendedor, actuando como agente oficioso de su hermano demandado, interpuso la excepción de nulidad de la obligación (por ausencia de voluntad conforme al artículo 1682 inciso segundo del $\mathrm{CC}^{50}$ ), conforme al mencionado artículo del CPC, la que fue, entonces, acogida.

El 21 de noviembre de 2006 se había inscrito al supuesto demente vendedor en el RND, constando que aquel padecía de $60 \%$ de discapacidad mental. El 5 de julio de 2013, tal vendedor celebró una compraventa del inmueble en cuestión, la que se encontraba inscrita con fecha 12 de julio de 2013. El 2 de septiembre de 2013 se solicita la declaración de interdicción por parte de la hermana del supuesto demente vendedor, declarándose la interdicción definitiva por sentencia recaída en procedimiento judicial voluntario, el 30 de octubre de 2013, esto es, solo 23 días después de haberse presentado la demanda ejecutiva por obligación de hacer por parte de la compradora.

La compradora apeló y la Corte de Apelaciones de Valparaíso acogió la apelación el 17 de noviembre de 2014, rechazando la excepción interpuesta y ordenando seguir adelante con la ejecución. El argumento de la Corte fue que el señalado artículo 464 número 14 del CPC se refiere a la nulidad de la obligación, es decir, a la existencia o validez del acto o contrato que da origen a la obligación; esta excepción no atañería al carácter ejecutivo del título, cuestión a la que se refiere más bien el numeral 7 del mencionado artículo del CPC ${ }^{51}$. Contra esta sentencia se interpone recurso de casación en el fondo. La Corte Suprema acoge la casación en el fondo, afirmando que se ha efectuado una errada interpretación del mencionado numeral 14, que es el que corresponde aplicar -y no el numeral 7-, ya que la nulidad alegada se relaciona con la falta de un requisito previsto por la ley para la validez del acto o contrato en que se sustenta la obligación materia de autos.

${ }^{48}$ Corte Suprema, 13.7.2015, rol 1985-2013.

${ }^{49}$ CPC, art. 464 número 14: "La oposición del ejecutado solo será admisible cuando se funde en alguna de las excepciones siguientes: (...) $14^{\mathrm{a}}$. la nulidad de la obligación”.

${ }^{50}$ CC, art. 1682 inc. 2: "Hay asimismo nulidad absoluta en los actos y contratos de personas absolutamente incapaces".

${ }^{51}$ CPC, art. 464 número 7: "La oposición del ejecutado solo será admisible cuando se funde en alguna de las excepciones siguientes: (...) $7^{\mathrm{a}}$. La falta de alguno de los requisitos o condiciones establecidos por las leyes para que dicho título tenga fuerza ejecutiva, sea absolutamente, sea con relación al demandado”. 
Lo que se desprende de este caso es que la situación de inscripción en el RND y el hecho de presentar el demandado una discapacidad severa conforme con las reglas del Decreto 47 permiten una presunción grave y con precisión suficiente para formar convencimiento de que a la fecha de celebración del contrato el vendedor sufría demencia habitual, sin razonar acerca de la competencia de la persona para tomar decisiones respecto de su propio patrimonio.

Analicemos ahora el fallo de la Corte de Apelaciones de Santiago, de 30 de mayo de $2016^{52}$, referido esta vez al procedimiento previsto en la Ley $\mathrm{N}^{\circ} 18.600$. En esta oportunidad, al resolver la aplicación del artículo 4 de la Ley $\mathrm{N}^{\circ} 18.600$, esta Corte señala que al juez no le compete constatar el cumplimiento de las exigencias legales, de forma tal que la evaluación de la capacidad de discernimiento queda asimilada o cubierta con el certificado de la discapacidad mental emitido por la autoridad competente, sin que sea necesario ningún otro tipo de evaluación profesional.

La Corte de Apelaciones entendió que la prueba rendida por el solicitante, valorada prudencialmente conforme con el artículo 819 del CPC, permitía acreditar que el sujeto padecía de una discapacidad mental psíquica severa, equivalente a $50 \%$, de carácter permanente, diagnosticada por la COMPIN, encontrándose además inscrita en el RND. Por ello, revocó la sentencia de primera instancia y declaró la interdicción, al entender satisfechas todas las exigencias legales. En el considerando tercero afirmó que:

"la impresión que el juez de la causa se forme respecto del estado de salud mental de la persona con discapacidad cuya declaración de interdicción se solicita, con motivo de la realización de la audiencia que prevé la ley, no puede sustituir el dictamen emitido por quienes profesan la ciencia de la medicina y que se desempeñan, precisamente, en el área de la salud mental, únicas personas que se encuentran profesionalmente capacitadas para proporcionar un diagnóstico de esa especificidad técnica. Lo anterior no importa que la audiencia referida sea superflua ni que el rol del juez en procedimientos de esta naturaleza sea irrelevante, sino únicamente que, en el evento de optarse por esta vía para obtener se decrete la interdicción por demencia de una persona y no por el pleito contencioso, el tribunal deberá limitarse a constatar el cumplimiento de las exigencias legales sobre la base de los antecedentes que se le hagan valer y efectuar las declaraciones que corresponda”.

Se ha dicho que la audiencia previa del juez con la PcDICPS supone una verdadera inspección del tribunal ${ }^{53}$, pero cuyo único fin es "corroborar" la discapacidad ${ }^{54}$, en especial

52 Corte de Apelaciones de Santiago, 30.5.2016, rol C-1304-2016.

${ }^{53} \mathrm{La}$ inspección personal del tribunal es fundamental, observándose su verificación en todas las causas revisadas al efectuar este trabajo. Parece primordial que el juez pueda dilucidar en primera persona el grado de discapacidad del presunto interdicto (este es un trámite esencial en el procedimiento voluntario, según establece el artículo 4 inciso segundo de la Ley $\mathrm{N}^{\circ}$ 18.600). En cambio, se observa que no existe un criterio uniforme por el cual el tribunal decida solicitar informe al defensor público.

${ }^{54}$ Cfr. López, 2016, p. 685. 
en los procedimientos voluntarios. Así también lo ha entendido la jurisprudencia: "en el evento de optarse por esta vía para obtener se decrete la interdicción por demencia de una persona y no por el pleito contencioso, el tribunal deberá limitarse constatar el cumplimiento de las exigencias legales sobre la base de los antecedentes que se le hagan valer y efectuar las declaraciones que corresponda" 55 . Este tipo de decisiones ignoran que la valoración judicial al conocer de la interdicción por demencia, sea cual sea el procedimiento, debe centrarse en la competencia de la persona para tomar decisiones autónomas acerca de aspectos de su propia vida: el juez descansa excesivamente en una resolución administrativa.

La falta de razonamiento judicial acerca de la competencia de la persona respecto de la que se solicita la interdicción, bajo el argumento de encontrarse certificada la discapacidad, conlleva la pérdida de un sinnúmero de derechos de distinta índole, según he comentado más arriba; en circunstancias de que, en muchas ocasiones, se trata más bien de situaciones de dependencia que requieren la asistencia de un cuidador, apoyo que puede ser proporcionado sin necesidad de declarar la interdicción. Así, por ejemplo, cuando se señala que una persona de 23 años -víctima de una hidrocefalia secundaria y que utiliza silla de ruedas-, respecto de la cual su madre solicita la interdicción por demencia, "entiende lo que se le pregunta pero se expresa con dificultad" y que "come sola pero se cansa, controla esfínter pero hay que llevarla al baño, vestirla, bañarla, entre otros actos", es posible preguntarse si la discapacidad psíquica o mental certificada de $80 \%$ es un antecedente tan esencial y contundente como para que el juez nombre a una persona autorizada para sustituir su voluntad en todo ámbito de su vida ${ }^{56}$.

\section{CONCLUSiOnes}

1. Las PcDICPS se ven enfrentadas a barreras legales y a prácticas discriminatorias en ámbitos de su libertad personal, relaciones familiares, salud, relaciones contractuales, derechos políticos y acceso a ciertos cargos y funciones, entre otros.

2. Leyes y reglamentos generales y especiales continúan utilizando denominaciones arbitrarias para referirse a ellas; más aún, el CC no ha adecuado sus reglas sobre capacidad e interdicción por demencia a los postulados de la Convención, habiendo sido avalada su legalidad y constitucionalidad por distintos órganos del Estado.

3. Las normas concernientes a interdicción por demencia no han sido adecuadas al paradigma social de la Convención. Estas normas vulneran los derechos de las PcDICPS - tanto mayores como menores de edad- al permitir la sustitución absoluta y desproporcionada de su voluntad mediante el nombramiento de un curador; en especial, su derecho a ejercer capacidad jurídica, a ser oídas y al debido proceso.

\footnotetext{
55 Corte de Apelaciones de Santiago, 2.4.2014, rol 7238-2013.

$563^{\text {er }}$ Juzgado Civil de Santiago, 20.12.2013, rol V-311-2013.
} 
4. La existencia de dos procedimientos judiciales de declaración de interdicción por demencia de distinta naturaleza, sumada a la curaduría provisoria de índole administrativa, ha generado problemas importantes tanto de tramitación como de ponderación judicial y, consecuentemente, de certeza jurídica.

- Se observa que los titulares de la solicitud o demanda, en su caso, no son los mismos; que el procedimiento administrativo autoriza ciertas excepciones a la sustitución absoluta de la voluntad del presunto demente, generando la existencia paralela de dos tipos de PcDICPS interdictas por demencia. Todos los procedimientos carecen de salvaguardas adecuadas de control; incluso más, el de carácter administrativo está desprovisto de las formalidades posteriores a la declaración de interdicción y permite que ella opere de pleno derecho, pudiendo transformarse en permanente, ya que no está sujeta a revisión periódica obligatoria.

- Es imposible saber con exactitud cuántas personas se encuentran declaradas interdictas por demencia. La existencia de una curaduría provisoria al margen de la intervención judicial que se prolonga de hecho en el tiempo provoca que haya interdicciones no registradas como tales o bien registros paralelos a lo ordenado judicialmente.

- Los tribunales observan tramitaciones y diligencias probatorias diversas, lo que genera incerteza jurídica respecto del procedimiento a seguir.

- La Ley $N^{\circ} 18.600$ no contempló los trámites posteriores al procedimiento que reguló, por lo que en la práctica se subentiende que las diligencias y formalidades que contempla el CC para el ejercicio de la curaduría deben cumplirse de todas formas (con lo que no todas las PcDICPS son protegidas por medio de ellas).

5. Finalmente, se observa confusión entre el diagnóstico técnico referido a la discapacidad intelectual y la valoración que el juez, conociendo de la interdicción, debe efectuar acerca de la competencia de la persona para tomar decisiones autónomas de aspectos de su propia vida. Las consecuencias que la interdicción por demencia acarrea son tan lesivas de la dignidad humana que constituye un imperativo ético ponderar cabalmente todo tipo de prueba allegada al proceso, así como determinar proporcionalmente al grado de discapacidad el apoyo que se requiere. Este apoyo es muchas veces de orden informal, pues, por el grado de dependencia -mas no de discapacidad intelectual- de la persona, lo que ellas necesitan es un cuidado digno, respetuoso de su voluntad, preferencias y deseos; siendo innecesaria la privación de sus derechos mediante la interdicción por demencia.

\section{BIBLIOGRAFÍA}

BACH, Michael y Kerzner, Lana, 2010: "A new paradigm for protecting autonomy and the right to legal capacity”. Disponible en www.lco-cdo.org/wp-content/uploads/2010/11/disabilitiescommissioned-paper-bach-kerzner.pdf. [Fecha de consulta: 15.05.2018]. 
Barcia Lehmann, Rodrigo, 2011: Fundamentos del Derecho de Familia y de la Infancia, Santiago, Thomson Reuters Puntolex.

Corporación de Asistencia Judicial, 2012: "Una mirada desde la práctica a la declaración de interdicción”. Disponible en docplayer.es/15022972-Una-mirada-desde-la-practica-ala-declaracion-de-interdiccion-introduccion-1-2.html. [Fecha de consulta: 15.05.2018].

Claro Solar, Luis, 1979: Explicaciones de Derecho Civil Chileno y Comparado, Tomo XI, Santiago, Editorial Jurídica de Chile.

Comité sobre los Derechos de las Personas con Discapacidad, 2016: "Observaciones finales sobre el informe inicial de Chile". Disponible en http://docstore.ohchr.org/SelfServices/ FilesHandler.ashx? enc $=6 \mathrm{QkG} 1 \mathrm{~d} \% 2 \mathrm{FPPRiCAqhKb} 7 \mathrm{yhsrBkvDLHrFFq} 8 \mathrm{wSOe} 2 \mathrm{z} 9 \mathrm{~g} 3 \mathrm{iFJkx}$ VdXG46rNMaDkVcT6SYCqE9w8saGfjQe6YuM2nEvOCVqR\%2BIFnDejMd18bZ3X3I RnxsnrlMuSYVwTSB\%2BQck [Fecha de consulta: 31.10.2018].

Corral Talciani, Hernán, 2011: "Interdicción de personas que sufren trastorno de dependencia a la cocaína", Revista de Derecho, vol. XXIV, núm. 2: pp. 31-64.

Dirección de Estudios de la Corte Suprema, 2017: "Análisis Estadístico de la Ley 20.609: Una mirada desde el acceso a la justicia a cinco años de su vigencia”. Disponible en decs. pjud.cl/documentos/descargas/Articulo_An_lisis_Estad_stico_de_la_Ley_20_609.pdf. [Fecha de consulta: 15.05.2018].

Fundación Descúbreme. Discapacidad Cognitiva. Recuperado el 15.05.2018, de Fundación Descúbreme: www.descubreme.cl/informacion. Fecha de consulta: 15 de Mayo de 2018.

Instituto Nacional de Estadísticas, 2017: “Justicia, Informe Nacional 2016”. Disponible en www.ine.cl/docs/default-source/publicaciones/2017/informe-anual-de-justicia-2016. pdf? sfvrsn=13. [Fecha de consulta: 14.05.2018].

López Díaz, Carlos, 2016: Tratado de Derecho de Familia, Santiago, Digesto.

Lyon Puelma, Alberto, 2007: Personas Naturales, Santiago, Ediciones Universidad Católica de Chile.

Ministerio De Salud, 2017: Plan Nacional de Demencia. Disponible en http://www.minsal.cl/ wp-content/uploads/2017/11/PLAN-DE-DEMENCIA.pdf [Fecha de consulta: 31.10.2018].

Observatorio de Derechos Humanos de las Personas con Discapacidad Mental, 2014 : Derechos Humanos de las Personas con Discapacidad Mental: Diagnóstico de la Situación en Chile. Disponible en www.senadis.gob.cl/descarga/i/3330. [Fecha de consulta: 15.05.2018].

Silva Barroilhet, Paula, 2017: La capacidad jurídica de las personas con discapacidad intelectual: régimen jurídico chileno y bases para su modificación, Santiago, Legal Publishing Chile.

Normas jurídicas citadas

Decreto No 47 del Ministerio de Salud, establece reglamento para la calificación y certificación de la discapacidad, publicado con fecha 16 de Octubre de 2013.

LEY $\mathrm{N}^{\circ} 20.609$, Establece medidas contra la discriminación, publicada con fecha 24 de Julio de 2012.

LEY N $\mathrm{N}^{\circ}$ 20.422, Establece normas sobre igualdad de oportunidad e inclusión social de personas con discapacidad, publicada con fecha 10 de Febrero de 2010.

Convención sobre los Derechos de las Personas con Discapacidad, adoptada el 13 de Diciembre de 2006. Ratificada por Chile mediante Decreto 201, publicado el 17 de Septiembre de 2008.

LEY $\mathrm{N}^{\circ}$ 19.954, modifica la Ley 18.600, en lo relativo al procedimiento de interdicción de los discapacitados mentales, publicada con fecha 14 de Julio de 2004.

LEY $\mathrm{N}^{\circ} 19.735$, modifica la Ley $\mathrm{N}^{\circ} 18.600$, estableciendo nuevas normas sobre los discapacitados mentales, publicada con fecha 22 de junio de 2001. 
D.F.L. $\mathrm{N}^{\circ} 1$, fija texto refundido, coordinado y sistematizado del Código Civil, publicado con fecha 30 de mayo de 2000.

LEY $\mathrm{N}^{\circ} 19.284$, establece normas para la plena integración social de las personas con discapacidad, publicada con fecha 14 de enero de 1994.

LEY $\mathrm{N}^{\circ} 18.600$, establece normas sobre deficientes mentales, publicada con fecha 19 de febrero de 1987.

LEy N ${ }^{\circ}$ 1.552, Código de Procedimiento Civil, publicada con fecha 30 de agosto de 1902.

\section{Jurisprudencia citada}

Corte Suprema, sentencia de 21 de Junio de 2018, rol 38521-2017.

Corte de Apelaciones de Santiago, sentencia de 30 de Mayo de 2016, rol C-1304-2016.

Tribunal Constitucional de Chile, sentencia de 2 de Enero de 2016, rol 2703-15.

Corte Suprema, sentencia de 17 de Diciembre de 2015, rol 27322-2014.

Corte de Apelaciones de Santiago, sentencia de 5 de Noviembre de 2015, rol 9316-2015.

Corte Suprema, sentencia de 13 de Julio de 2015, rol 1985-2013.

Corte de Apelaciones de Copiapó, sentencia de 12 de Diciembre de 2014, rol 397-2014.

Corte de Apelaciones de Santiago, sentencia de 2 de Abril de 2014, rol 7238-2013.

$3^{\circ}$ Juzgado Civil de Santiago, sentencia de 20 de Diciembre de 2013, rol V-311-2013.

Contraloría General de la República, dictamen No 27016, de 10 de Mayo de 2012. 